\title{
Yukmijihwang-Tang Suppresses Receptor Activator of Nuclear Factor Kappa-B Ligand (RANKL)-Induced Osteoclast Differentiation and Prevents Ovariectomy (OVX)-Mediated Bone Loss
}

\author{
Sang-Yong Han ${ }^{1,2}$ and Yun-Kyung Kim ${ }^{1,2, *(D)}$ \\ 1 Department of Herbal Medicine, College of Pharmacy, Wonkwang University, 460 Iksandae-ro, Iksan 54538, \\ Korea; 030745@daum.net \\ 2 Wonkwang Oriental Medicines Research Institute, Wonkwang University, 460 Iksandae-ro, Iksan 54538, Korea \\ * Correspondence: hestia@wku.ac.kr; Tel.: +82-63-850-6803
}

\section{check for}

updates

Citation: Han, S.-Y.; Kim, Y.-K. Yukmijihwang-Tang Suppresses Receptor Activator of Nuclear Factor Kappa-B Ligand (RANKL)-Induced Osteoclast Differentiation and Prevents Ovariectomy (OVX)-Mediated Bone Loss. Molecules 2021, 26, 7579. https://doi.org/ $10.3390 /$ molecules 26247579

Academic Editors: Farid Chemat and Jetze J. Tepe

Received: 30 November 2021

Accepted: 10 December 2021

Published: 14 December 2021

Publisher's Note: MDPI stays neutral with regard to jurisdictional claims in published maps and institutional affiliations.

Copyright: (c) 2021 by the authors. Licensee MDPI, Basel, Switzerland. This article is an open access article distributed under the terms and conditions of the Creative Commons Attribution (CC BY) license (https:// creativecommons.org/licenses/by/ $4.0 /)$.
Abstract: Yukmijihwang-tang (YJ) has been used to treat diabetes mellitus, renal disorders, and cognitive impairment in traditional medicine. This study aimed to evaluate the anti-osteoporotic effect of $\mathrm{YJ}$ on ovariectomy (OVX)-induced bone loss in a rat and receptor activator of nuclear factor kappa-B ligand (RANKL)-mediated osteoclast differentiation in bone marrow macrophages (BMMs). YJ reduced the formation of tartrate-resistant acid phosphatase (TRAP)-positive multinucleated cells (MNCs) in an osteoclast/osteoblast co-culture system by regulating the ratio of RANKL/osteoprotegerin (OPG) by osteoblasts. Overall, YJ reduced TRAP-positive cell formation and TRAP activity and F-actin ring formation. Analysis of the underlying mechanisms indicated that $\mathrm{YJ}$ inhibited the activation of the nuclear factor of activated T cell cytoplasmic 1 (NFATc1) and c-Fos, resulting in the suppression of osteoclast differentiation-related genes such as TRAP, ATPase, $\mathrm{H}+$ transporting, lysosomal $38 \mathrm{kDa}$, V0 subunit d2, osteoclast-associated receptor, osteoclast-stimulatory transmembrane protein, dendritic cell-specific transmembrane protein, matrix metalloproteinase-9, cathepsin K, and calcitonin receptor. YJ also inhibited the nuclear translocation of NFATc1. Additionally, YJ markedly inhibited RANKL-induced phosphorylation of signaling pathways activated in the early stages of osteoclast differentiation including the p38, JNK, ERK, and NF-KB. Consistent with these in vitro results, the YJ-administered group showed considerably attenuated bone loss in the OVX-mediated rat model. These results provide promising evidence for the potential novel therapeutic application of $\mathrm{YJ}$ for bone diseases such as osteoporosis.

Keywords: Yukmijihwang-tang; osteoclast differentiation; RANKL; NFATc1; OVX; bone loss

\section{Introduction}

Osteoporosis is a common disorder of bone remodeling characterized by loss of bone mass and density, which results in an increased risk of fractures [1]. Osteoporosis is related to various factors, such as age, menopause, and chronic medical conditions, and is correlated with increased mortality in the elderly due to the fact of pathological fractures. It can be classified into two subtypes: type I and type II osteoporosis. Type I osteoporosis, also known as postmenopausal osteoporosis, is caused by estrogen deficiency after menopause, and it mainly affects trabecular bone resorption. Postmenopausal osteoporosis occurs in women, typically between the ages of 50 and 65 years, and signals the end of the fertile phase of the life cycle of a woman. Type II osteoporosis is also called senile osteoporosis and is characterized by age-related loss of cortical and trabecular bone in women and men [2-4]. Currently, numerous therapeutic agents are being used to treat osteoporosis. They are usually classified as either anabolic drugs or anti-resorptive drugs. These drugs increase bone mineral density and decrease the risk of skeletal fractures. Anabolic agents, including teriparatide and abaloparatide, increase bone strength and bone formation. 
Anti-resorptive agents, such as estrogen, bisphosphonates, and selective estrogen receptor modulators (SERMs), increase bone mass by reducing the function of osteoclasts. However, almost all of these drugs have considerable side effects, including osteonecrosis of the jaw (ONJ), hypocalcemia, and gastrointestinal disorders, due to the long-term treatment $[5,6]$. Therefore, recent experimental studies have focused on the development of new drugs from natural products, including plant extracts, with fewer side effects for the prevention or treatment of osteoporotic bone diseases.

Bone remodeling is a tightly stimulated natural process that requires removal of old bone by osteoclasts and formation of new bone by osteoblasts. Regulation of bone remodeling occurs by various mechanisms related to the interaction between osteoclasts and osteoblasts $[7,8]$. Osteoclasts are multinucleated giant cells that differentiate from mononuclear cells of the monocyte/macrophage lineage upon stimulation by two fundamental factors: M-CSF and RANKL $[9,10]$. M-CSF regulates the proliferation and survival of osteoclast precursors via c-Fms and the M-CSF receptor [11]. The TNF superfamily member, RANKL, which is secreted by osteoblasts and activated T cells, is the major factor involved in osteoclast differentiation [12]. OPG acts as a decoy receptor and prevents the interaction of RANKL with its receptor RANK, eventually leading to suppression of RANKL-activated osteoclastogenesis [13]. Thus, the RANKL/RANK/OPG signaling pathway regulates bone remodeling at multiple levels, including osteoclast formation and function [14]. The binding of RANKL to its receptor RANK leads to the recruitment of TNF receptor-associated factors (TRAFs), such as TRAF6, and eventually regulates multiple downstream signaling pathways, including MAPKs, the PI3K/Akt pathway, and NF- $\kappa B$, leading to the upregulation of the transcription factors c-Fos and NFATc1 that are required for osteoclast differentiation [15-17]. Subsequently, activated NFATc1 induces the expression of several osteoclast-specific genes, such as OSCAR, TRAP, calcitonin receptor, cathepsin K, MMP-9, Atp6v0d2, DC-STAMP, and OC-STAMP, which are important for osteoclast formation and function [18-22]. YJ is a multi-herb formula that is widely used in East Asia. YJ consists of six herbal medicines including Rehmanniae Radix Preparata, Corni Fructus, Poria, Dioscoreae Rhizoma, Alismatis Rhizoma, and Moutan Cortex Radicis. Traditionally, YJ has been used to treat clinical kidney yin deficiency symptoms such as hectic fever, dizziness, dry mouth and throat, excessive thirst and liquid intake, spermatorrhea, night sweats, red tongue with less coating, and rapid pulse [23]. Several pharmacological properties of YJ have been reported such as protection against renal ischemia/reperfusion [24], improvement in learning and memory [25], anti-obesity [26], anti-diabetic [27], and antioxidant effects [28]. In particular, YJ repressed RANKL-induced osteoclast differentiation in RAW264.7 cells [29] and reduced parathyroid hormone-mediated bone loss and bone resorption in OVX rats [30]. In this study, we examined the pharmacological effects of YJ on RANKL-mediated osteoclast differentiation in BMMs and animal models of OVX-induced bone destruction.

\section{Results}

\subsection{High-Performance Liquid Chromatography (HPLC) Analysis of YJ Water Extracts}

HPLC analysis simultaneously identified five marker components of YJ: 5-hydroxymethyl2-furaldehyde (5-HMF) of Rehmanniae Radix Preparata, Alisol A of Alismatis Rhizoma, diosgenin of Dioscoreae Rhizoma, loganin of Corni Fructus, and paeonol of Moutan Cotex Radicis. The five components were recorded with the same retention times as window as studied previously. Alisol A (1), 5-HMF (2), diosgenin (3), loganin (4), and paeonol (5) (Figure 1). 


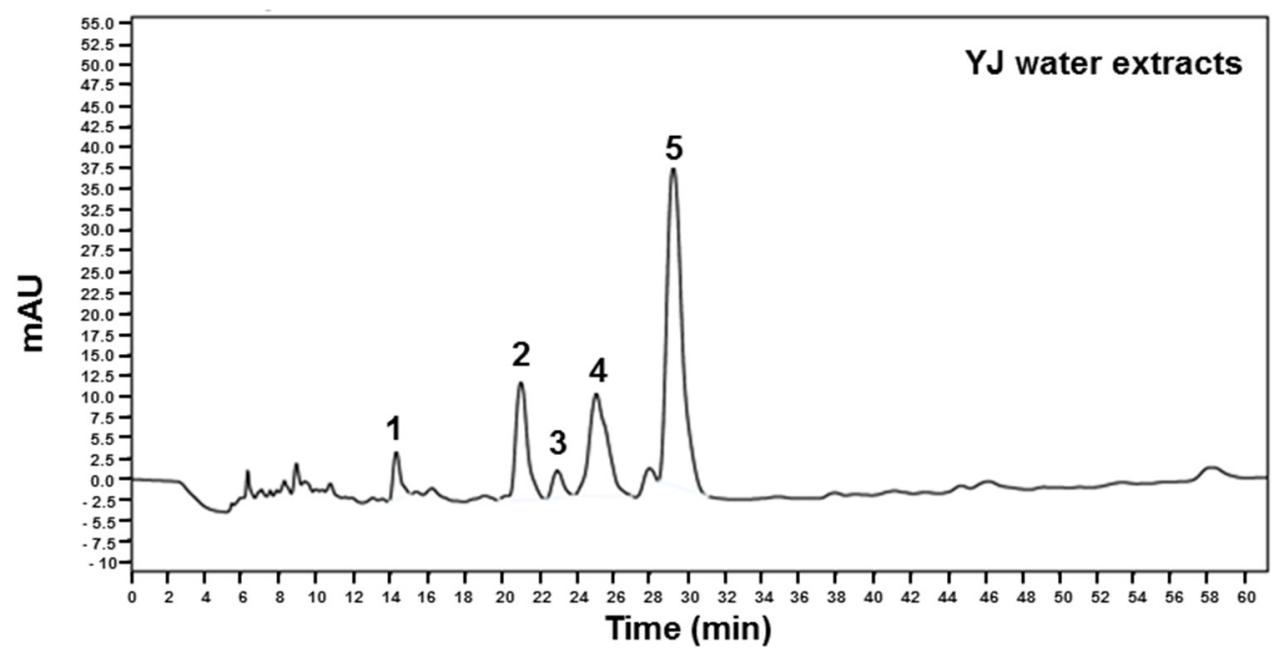

(a)

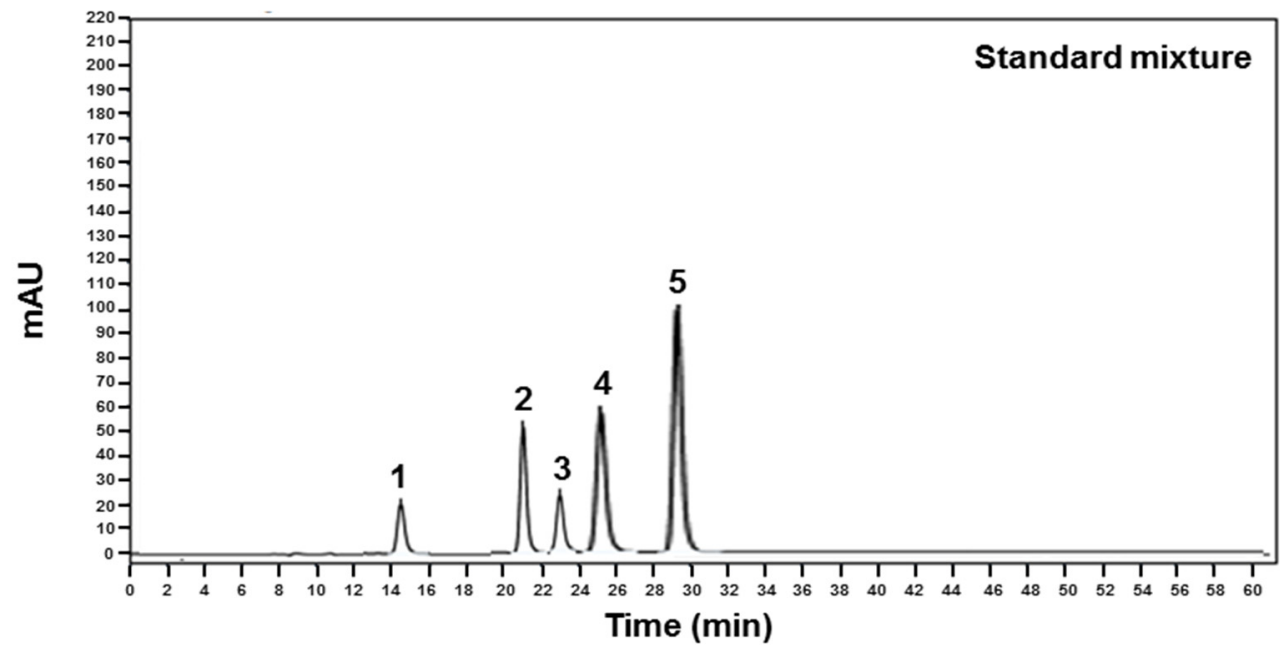

(b)

Figure 1. HPLC analysis of the YJ water extracts (a) and its reference standard (b). Peak identification: 1-Alisol A; 2-5-hydroxymethyl-2-furaldehyde (5-HMF); 3-diosgenin; 4-loganin; 5-paeonol.

\subsection{YJ Inhibited Osteoclast Differentiation in the Co-Culture System of BMCs and Osteoblasts}

We examined whether $\mathrm{YJ}$ was concerned in the formation of TRAP-positive MNCs in the co-culture system of bone marrow cells (BMCs) and osteoblasts. As shown in Figure 1a, YJ markedly inhibited prostaglandin E2 (PGE2)- and 1,25-dihydroxyvitamin (vit $\mathrm{D}_{3}$ )-activated formation of TRAP-positive MNCs in the co-culture system. YJ significantly reduced the number of PGE2-and vitamin $\mathrm{D}_{3}$-mediated TRAP-positive osteoclasts in a dose-dependent manner (Figure 2b,c). Cell cytotoxicity was not affected by treatment with YJ (Figure 2d). We next examined the effects of YJ on the expression of RANKL and OPG in co-cultured cells treated with PGE2 and vit $\mathrm{D}_{3}$ using reverse transcription polymerase chain reaction (RT-PCR). Treatment of co-cultured cells with PGE2 and vit $\mathrm{D}_{3}$ enhanced the expression of RANKL and suppressed the expression of OPG. YJ had a suppressive effect on the upregulation of RANKL mRNA expression but had promotive effects on the OPG mRNA expression levels (Figure 2e). To confirm these results, the expression levels of RANKL and OPG mRNA were assessed by quantitative real-time PCR. As shown in Figure $2 \mathrm{f}$, the mRNA expression of RANKL was significantly lower, while that of OPG was consistently higher when the cells were treated with YJ compared with the PGE2- and vit $\mathrm{D}_{3}$-treated control. These results demonstrate that $\mathrm{YJ}$ negatively regulated the formation of osteoclasts in the co-culture system by modulating the expression of RANKL and OPG. 


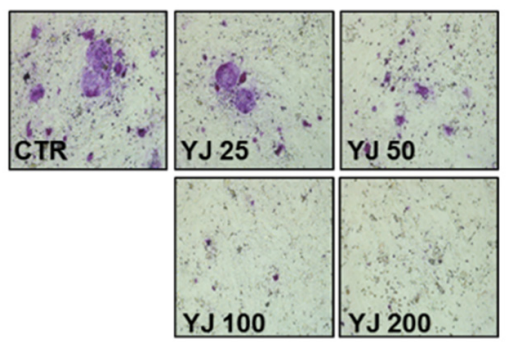

(a)

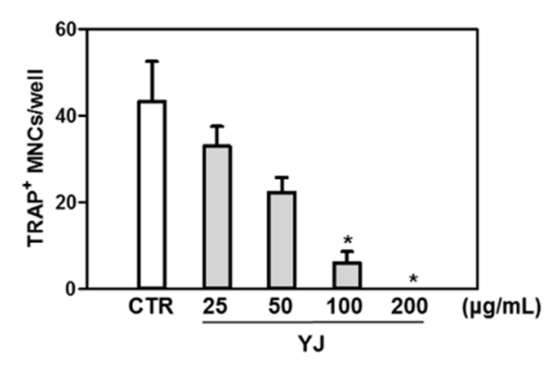

(c)

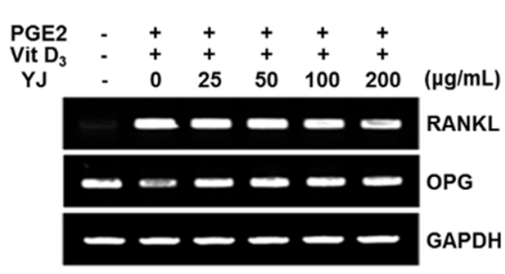

(e)

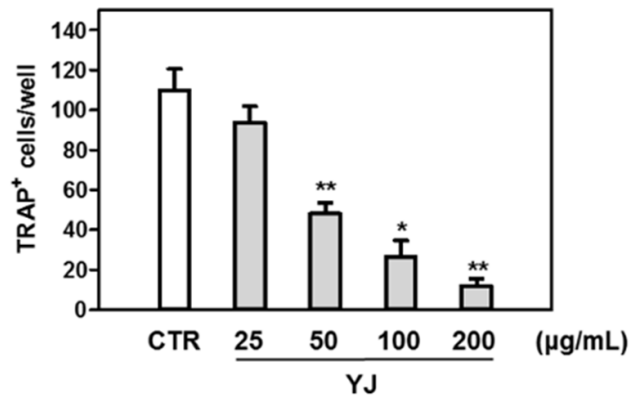

(b)

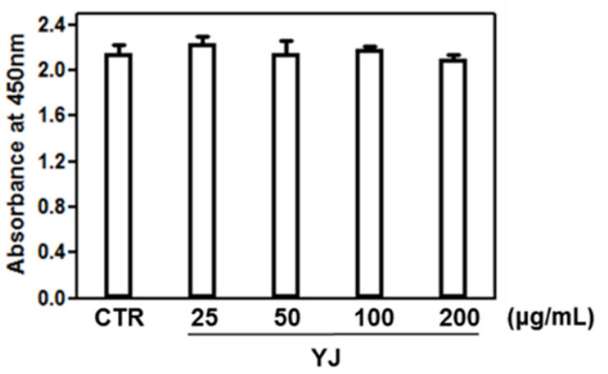

(d)
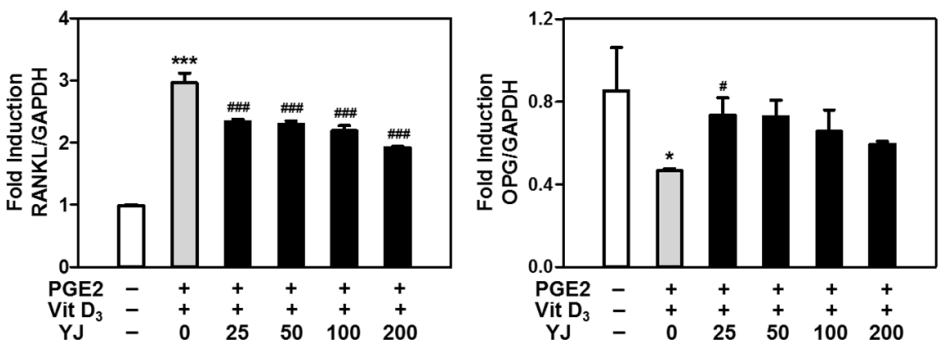

(f)

Figure 2. YJ suppressed osteoclastogenesis in the co-culture of bone marrow cells (BMCs) and mouse calvaria-derived osteoblasts. (a) BMCs and mouse calvaria-derived osteoblasts were co-cultured for 7 days in a medium containing vit $\mathrm{D}_{3}$ and PGE2 in the presence of YJ. Cells were fixed, permeabilized, and stained with TRAP solution. Images were captured under a light microscope $(100 \times$ magnification). (b,c) TRAP-positive cells and TRAP-positive MNCs with more than three nuclei were counted. (d) Co-cultured cells were seeded into a 96-well plate and cultured for 4 days. After 4 days, cell viability was analyzed using the XTT assay. (e) Total RNA was extracted from the cells, and the mRNA levels of OPG, RANKL, and GAPDH (glyceraldehyde 3-phosphate dehydrogenase) were measured using RT-PCR. For RT-PCR analysis, the PCR products were electrophoresed on a $1.5 \%$ agarose gel and were visualized by ethidium bromide staining. (f) Quantitative real-time RT-PCR was performed to determine the mRNA expression of OPG and RANKL. Data are presented as the mean \pm SD of four independent experiments. ${ }^{*} p<0.05,{ }^{* *} p<0.01^{* * *} p<0.001$ vs. the control group and ${ }^{\#} p<0.05,{ }^{\# \# \#} p<0.001$ vs. the vitamin $\mathrm{D}_{3}$ - and PGE2-treated group.

\subsection{YJ Inhibited RANKL-Mediated Osteoclast Differentiation in BMMs}

To verify the effects of YJ in RANKL-mediated osteoclast differentiation, primary BMMs were treated with M-CSF and RANKL in the presence or absence of 25, 50, 100, or $200 \mu \mathrm{g} / \mathrm{mL}$ YJ. In the YJ-untreated group, mature TRAP-positive MNCs occurred. However, YJ treatment reduced osteoclast differentiation as shown in images from a light microscope (Figure 3a). YJ treatment significantly inhibited the number of TRAP-positive MNCs (Figure 3b). These inhibitory effects of YJ did not affect the cell viability at any of the concentrations $(25,50,100$, and $200 \mu \mathrm{g} / \mathrm{mL})$ (Figure 3c). In addition, formation of the F-actin ring by fusion of osteoclasts was suppressed by YJ (Figure 3d). In this study, TRAP-positive MNCs were defined as having three or more nuclei. As shown Figure 3, we observed that the TRAP-positive multinucleated cells (MNCs) were indicated 
at three concentration of YJ $(25,50$, and $100 \mu \mathrm{g} / \mathrm{mL})$. On the basis of these results, we were concerned about the possibility of the group treated with 25,50 , and $100 \mu \mathrm{g} / \mathrm{mL}$ of YJ (the number of TRAP MNCs at each concentration were 145, 63, and 18 on average) differentiating into osteoclasts later, because in the figure, the cells treated with 25,50 , and $100 \mu \mathrm{g} / \mathrm{mL}$ of YJ still had multiple nuclei. Therefore, we used $200 \mu \mathrm{g} / \mathrm{mL}$ of YJ that did not show the possibility of osteoclast differentiation.

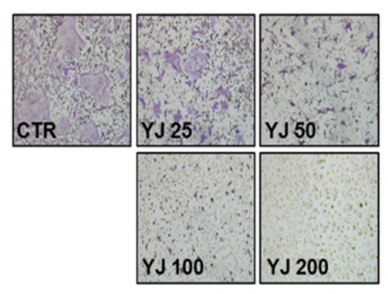

(a)

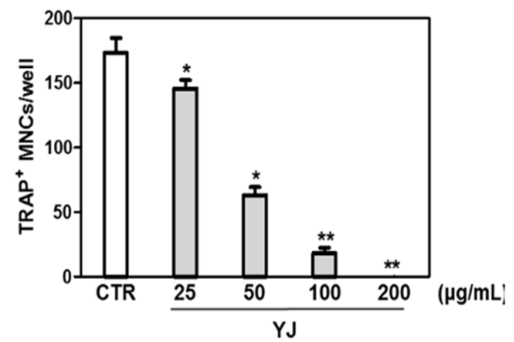

(b)

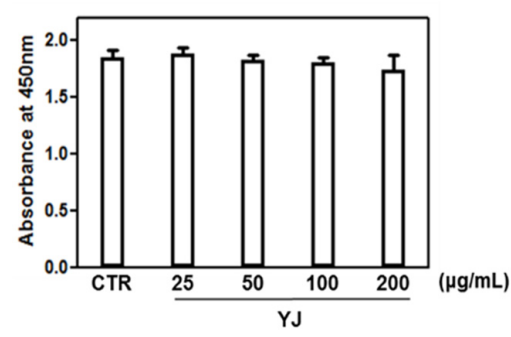

(c)

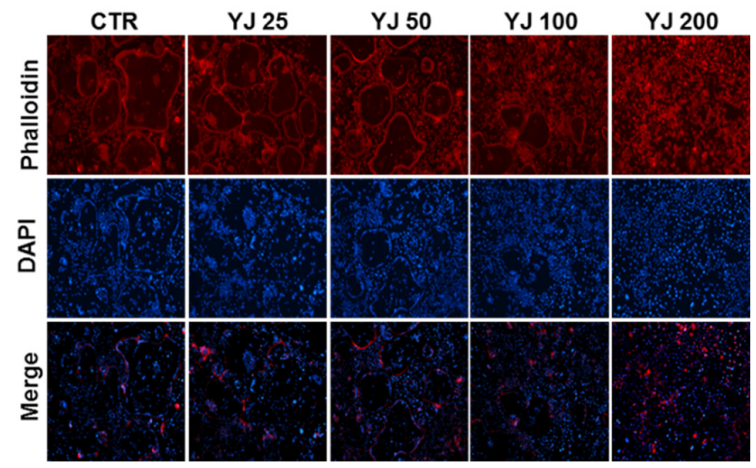

(d)

Figure 3. YJ suppressed RANKL-mediated TRAP-positive osteoclast formation. Bone marrow macrophages (BMMs) were cultured in differentiation medium containing M-CSF $(30 \mathrm{ng} / \mathrm{mL})$ and RANKL $(100 \mathrm{ng} / \mathrm{mL})$ for 4 days with vehicle or YJ $(n=4)$. (a) BMMs were fixed, permeabilized, and stained with TRAP solution. Images were captured under a light microscope (100× magnification). (b) TRAP-positive MNCs were counted on day 4. TRAP-positive MNCs with $>3$ nuclei were counted as osteoclasts. (c) After YJ treatment for 4 days, cell viability was measured by XTT assay. (d) Cells were fixed with $3.7 \%$ formalin, permeabilized with $0.1 \%$ Triton X-100, and stained with phalloidin (red) and DAPI (blue). Images were obtained by fluorescence microscope $(100 \times$ magnification). The data presented are the mean \pm SD of four independent experiments. ${ }^{*} p<0.05,{ }^{* *} p<0.01$ vs. the control group.

\subsection{YJ Inhibited RANKL-Mediated MAPK Signaling Pathway in BMMs}

To examine the mechanism underlying the YJ-mediated suppression of osteoclast differentiation, we examined the effects of YJ on RANKL-induced early activation of MAPKs (including p38, JNK, and ERK), Akt, and NF- kB signaling pathways, which are fundamental for osteoclast differentiation and function. RANKL-induced phosphorylation of p38, JNK, ERK, and Akt reached the maximum level at the time point of 5 min, whereas it markedly decreased in the group treated with $200 \mu \mathrm{g} / \mathrm{mL}$ of YJ (Figure $4 \mathrm{a}$ ). In addition, we evaluated the effect of YJ on the phosphorylation of NF- $\kappa$ B and degradation of I $\kappa$ B by Western blotting. RANKL stimulation led to the phosphorylation of NF- $\mathrm{KB}$ and degradation of I $\kappa \mathrm{B}$, whereas YJ treatment decreased RANKL-induced NF- $\kappa$ B and I $\mathrm{B}$ expression at $5 \mathrm{~min}$ (Figure $4 \mathrm{~b}$ ). Furthermore, we investigated the inhibitory effect of $\mathrm{YJ}$ on NF- $\mathrm{BB}$ transcriptional activity in 293T cells using the luciferase reporter assay. YJ significantly reduced the NF- $\kappa$ B transcription activity in a dose-dependent manner (Figure $4 \mathrm{c}$ ). These results indicate that $\mathrm{YJ}$ might abrogate osteoclastogenesis via the inhibition of RANKLmediated activation of p38, JNK, ERK, Akt, and NF-kB. 


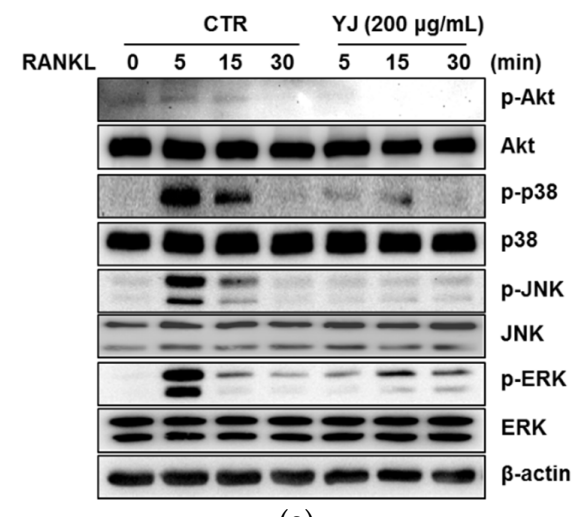

(a)

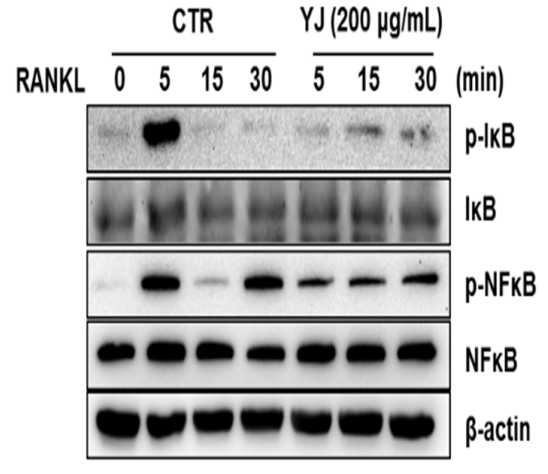

(b)

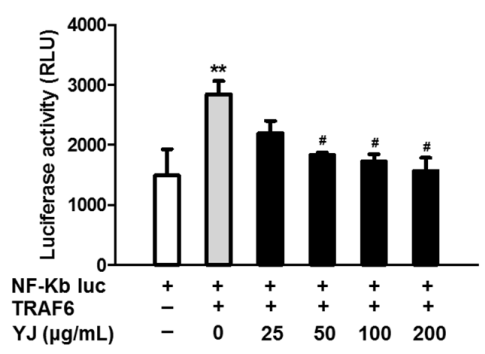

(c)

Figure 4. YJ suppresses RANKL-mediated early signaling in osteoclast differentiation. (a,b) BMMs were serum-starved for $2 \mathrm{~h}$ and pre-treated with $\mathrm{YJ}(200 \mu \mathrm{g} / \mathrm{mL})$ for $1 \mathrm{~h}$ and then treated with RANKL (100 ng/mL) for the indicated time. The cell lysates were evaluated by Western blotting. (c) 293T cells were co-transfected with TRAF6 and NF-kB-luciferase reporter plasmid. Luciferase activity was assayed using a luciferase assay system. The data presented are the mean $\pm \mathrm{SD}$ of three independent experiments. ${ }^{* *} p<0.01$ vs. the control group and ${ }^{\#} p<0.01$ vs. the TRAF6-stimulated group. TRAF6, TNF receptor-associated factor 6 .

\subsection{YJ Inhibited RANKL-Mediated NFATc1 and c-Fos Expression in BMMs}

NF-kB is known to be the regulated upstream factor of NFATc1 and c-Fos during RANKL-activated osteoclastogenesis [31]. To identify the inhibitory effect of YJ on osteoclast differentiation, we measured the RANKL-induced activation of NFATc1 and c-Fos. c-Fos mRNA and protein expression levels reached a maximum at $6 \mathrm{~h}$ after exposure to RANKL, while those of NFATc1 were elevated after $24 \mathrm{~h}$ of RANKL incubation and peaked at $48 \mathrm{~h}$. Quantitative real-time RT-PCR analysis indicated that YJ significantly suppressed c-Fos and NFATc1 expression at 6 and $48 \mathrm{~h}$, respectively (Figure $5 \mathrm{a}, \mathrm{b}$ ). At the same time, RANKL-mediated mRNA expression of c-Fos and NFATc1 was lowered by $\mathrm{YJ}$, in a dose-dependent manner (Figure $5 \mathrm{c}, \mathrm{d}$ ). In addition, Western blot analysis showed that NFATc1 and c-Fos protein expression were prominently decreased by YJ treatment (Figure 5e,f). NFATc1 is a transcription factor for the last stages of osteoclast differentiation and is activated by RANKL stimulation via nuclear translocation. To further determine whether YJ reduced NFATc1 translocation in the nucleus, we investigated the effect of YJ on the nuclear localization in mature osteoclasts. RANKL-treated cells demonstrated augmented nuclear translocation of NFATc1 compared to the controls. However, YJ stimulation attenuated the RANKL-induced translocation of NFATc1 to the nuclei (Figure 6a). We also measured the nuclear translocation of NFATc1 using nuclear/cytosol fraction kit. RANKL significantly promoted the nuclear translocation of NFATc1; however, it was blocked by YJ treatment (Figure $6 \mathrm{~b}$ ). These results demonstrated that the suppression of NFATc1 and c-Fos activation and blockage of nuclear translocation of NFATc1 are critical steps in the reduction of osteoclast differentiation by $\mathrm{YJ}$. 


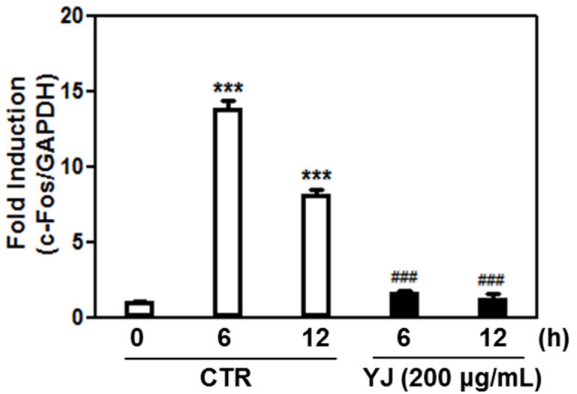

(a)

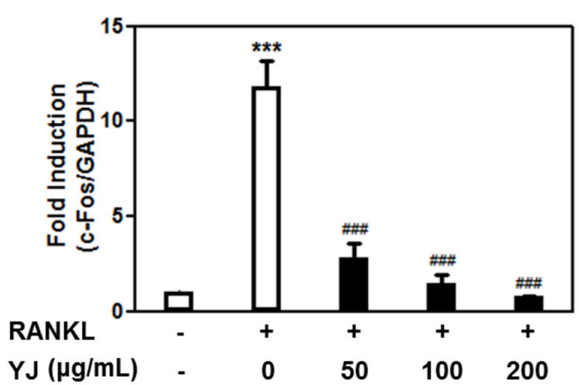

(c)

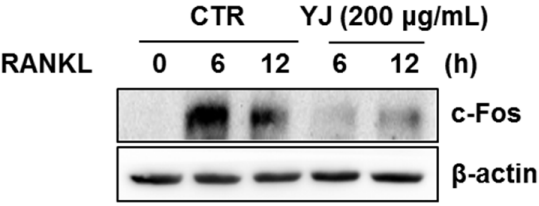

(e)

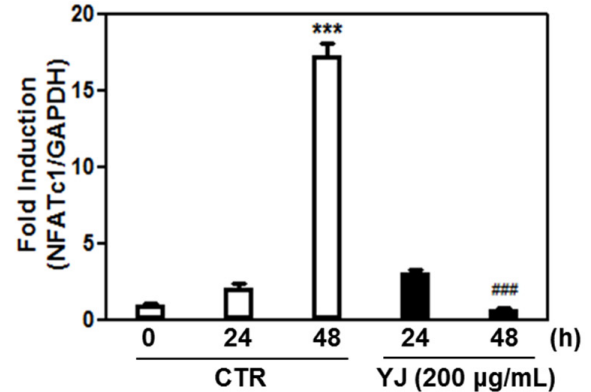

(b)

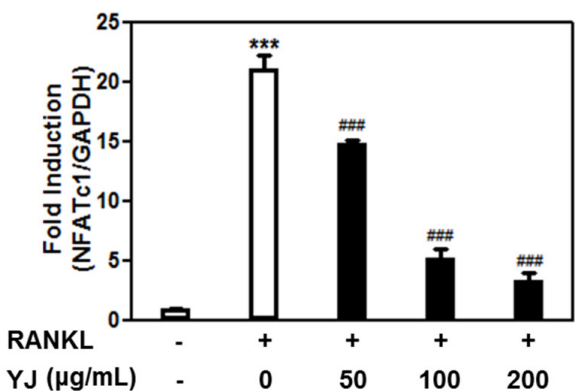

(d)

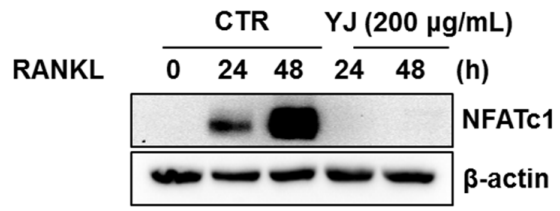

(f)

Figure 5. YJ suppressed RANKL-mediated expression of c-Fos and NFATc1 in BMMs. BMMs were treated with M-CSF and RANKL in the presence or absence of YJ $(200 \mu \mathrm{g} / \mathrm{mL})$ for the indicated time. (a-d) Total RNA was isolated from cells and mRNA expression levels of c-Fos and NFATc1 were measured by quantitative real-time RT-PCR. (e,f) The cell lysates were subjected to Western blot analysis with c-Fos and NFATc1 antibodies. $\beta$-actin was used as a loading control. The data are presented as the mean $\pm \mathrm{SD}$ of three independent experiments. ${ }^{* * *} p<0.001$ vs. the control group and ${ }^{\# \# \#} p<0.001$ vs. the RANKL-treated group at indicated times and concentrations.

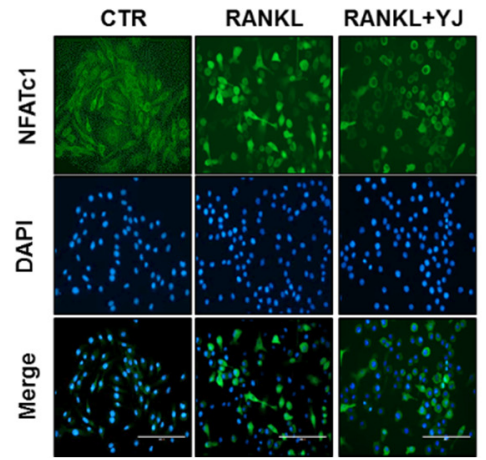

(a)

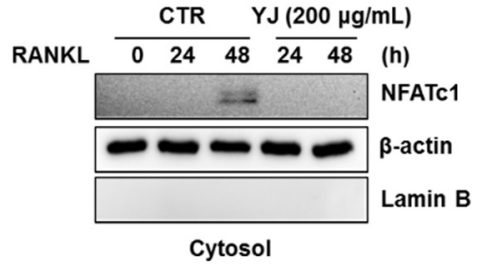

(b)

Figure 6. YJ suppresses RANKL-mediated nuclear translocation of NFATc1. The BMMs were treated with M-CSF and RANKL in the presence or absence of YJ $(200 \mu \mathrm{g} / \mathrm{mL})$. (a) Cells were fixed with $4 \%$ paraformalin, permeabilized with $0.1 \%$ Triton X-100, and stained with NFATc1 antibody (green) and DAPI (blue). (b) Nuclear and cytoplasmic fractions were analyzed using Western blot analysis. Lamin B and $\beta$-actin served as the loading controls for nuclear and cytoplasmic proteins, respectively. The data are presented as the mean \pm SD of three independent experiments. 


\subsection{YJ Reduced RANKL-Mediated Expression of Osteoclast-Related Genes in BMMs}

To elucidate the mechanisms underlying the inhibitory effect of YJ on RANKLactivated osteoclast differentiation, we determined the expression of osteoclast-related genes. Our data showed that the mRNA expression of TRAP, Atp6v0d2, OSCAR, OCSTAMP, DC-STAMP, MMP-9, calcitonin receptor, and cathepsin K were significantly upregulated upon exposure to RANKL at the time point of $48 \mathrm{~h}$ (Figure 7). However, YJ downregulated the mRNA expressions of TRAP and OSCAR, which were correlated with osteoclast differentiation. Moreover, YJ significantly attenuated mRNA expressions of Atp6v0d2, OC-STAMP, and DC-STAMP, which are required for osteoclast fusion (Figure 7). The expressions of transcription factors correlated with bone resorption, such as calcitonin receptor, MMP-9, and cathepsin K, were markedly reduced by YJ treatment (Figure 7). These results further showed that the inhibitory effect of YJ on RANKL-induced osteoclast differentiation, resorption, and fusion could be mediated through regulation of the activation of osteoclast-related genes.
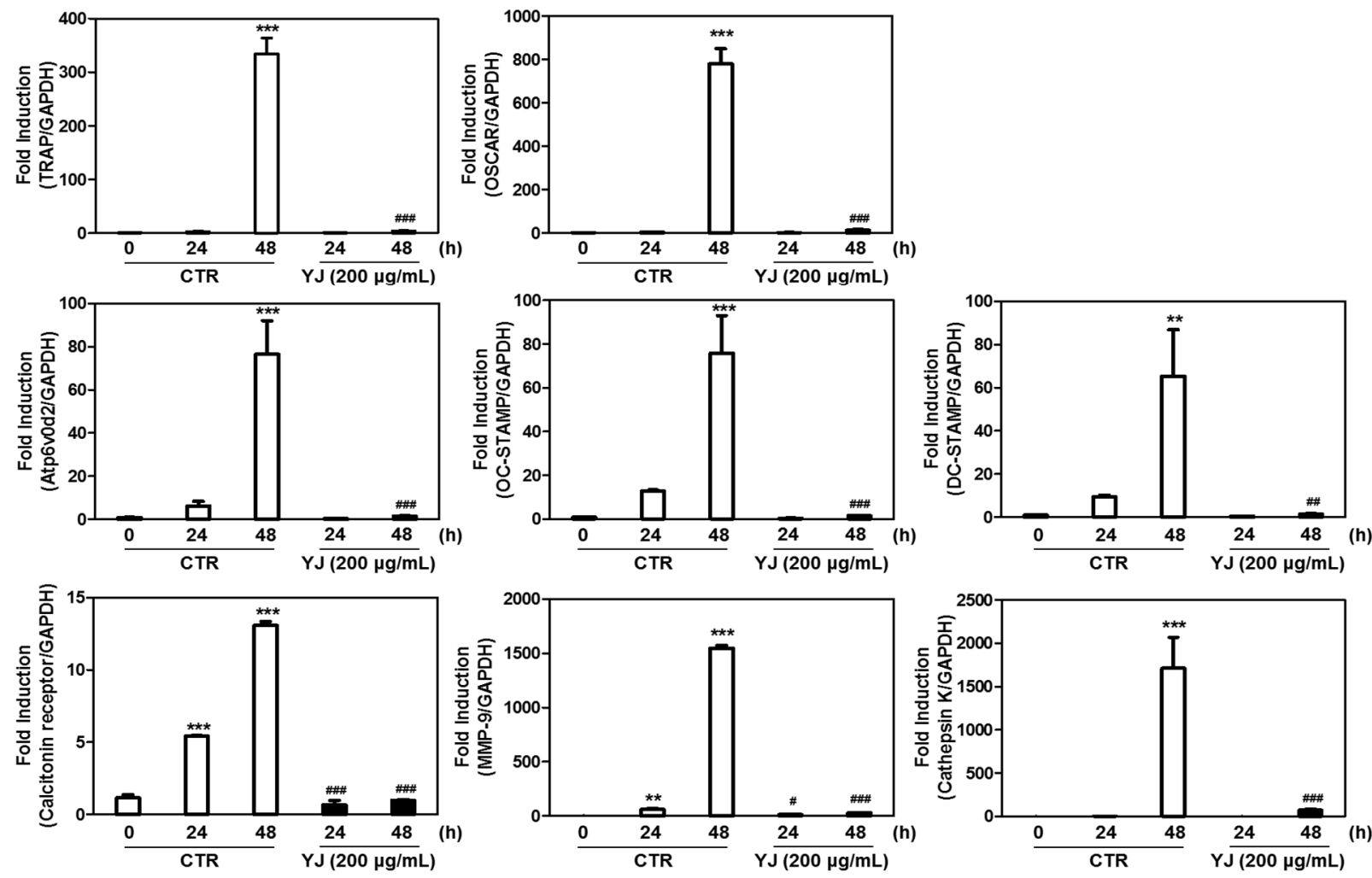

Figure 7. YJ suppresses RANKL-mediated expression of osteoclast-related genes in BMMs. BMMs were treated with M-CSF and RANKL in the presence or absence of YJ $(200 \mu \mathrm{g} / \mathrm{mL})$. Total RNA was isolated from cells and the mRNA expression of the indicated gene was analyzed by quantitative real-time RT-PCR. The data are presented as the mean \pm SD of three independent experiments. ${ }^{* *} p<0.01,{ }^{* * *} p<0.001$ versus the control at $0 \mathrm{~h} ;{ }^{\#} p<0.05,{ }^{\# \#} p<0.01,{ }^{\# \#} p<0.001$ versus the control at each time point. TRAP, tartrate resistant acid phosphatase; OSCAR, osteoclast-associated receptor; Atp6v0d2, vacuolar-type $\mathrm{H}^{+}$-ATPase V0 subunit D2; OC-STAMP, osteoclast stimulatory transmembrane protein; DC-STAMP, dendritic cell-specific transmembrane protein; MMP-9, matrix metalloproteinase-9.

\subsection{YJ Led to Increased Bone Density in the OVX Rat Model}

Based on the anti-osteoclast differentiation effect of $\mathrm{YJ}$ in vitro, the in vivo antiosteoporotic effect of $\mathrm{YJ}$ was tested in an experimental rat model of OVX-induced bone loss. 3D visualization of the femoral area by micro-CT revealed a loss of trabecular bone by OVX, which was reduced in the OVX- and YJ-treated rat (Figure 8a). Morphometric analysis of femurs of OVX rats indicated a decrease in bone volume/tissue volume (BV/TV), trabecular thickness (Tb.Th), and trabecular number (Tb.N) in comparison to the sham 
group. The BV/TV and Tb.N levels were considerably restored by 200 and $400 \mathrm{mg} / \mathrm{kg}$ YJ treatment; however, Tb.Th remained unaffected in these rats (Figure $8 b$ ). In contrast, trabecular separation (Tb.Sp) was higher in the OVX group than that in the sham group and decreased as a result of $Y \mathrm{~J}$ treatment (Figure $8 \mathrm{~b}$ ). Furthermore, histological analysis revealed that $\mathrm{YJ}$ treatment reduced OVX-induced bone loss in the femurs of OVX rats (Figure 8c). These findings demonstrated that $\mathrm{YJ}$ restores OVX-mediated bone destruction.

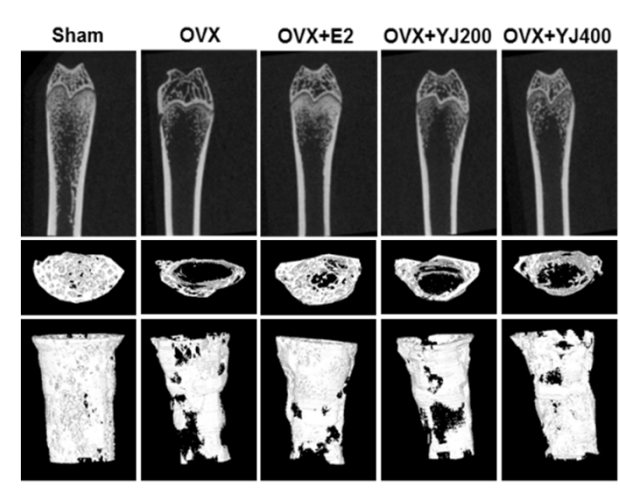

(a)
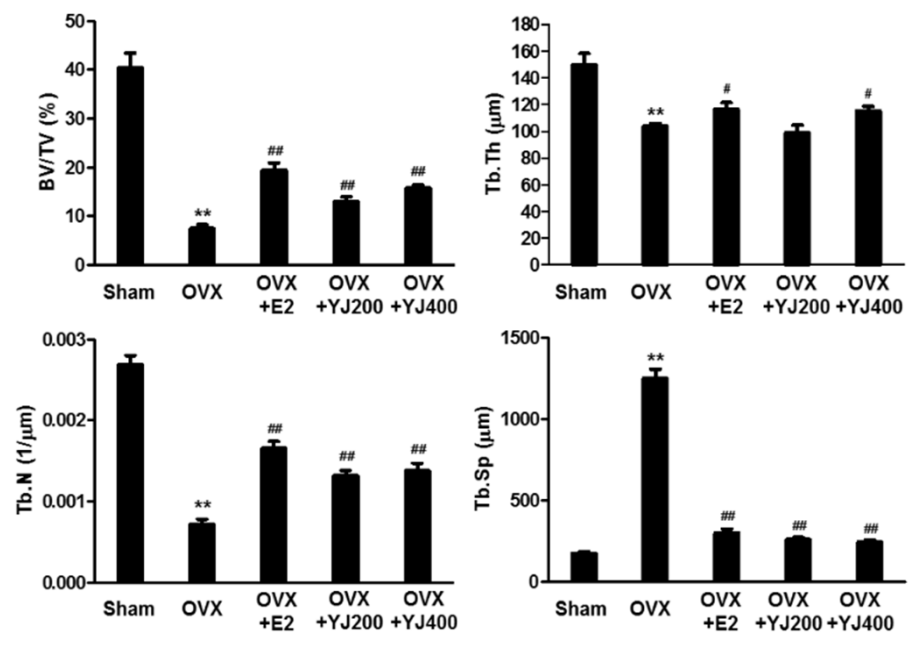

(b)

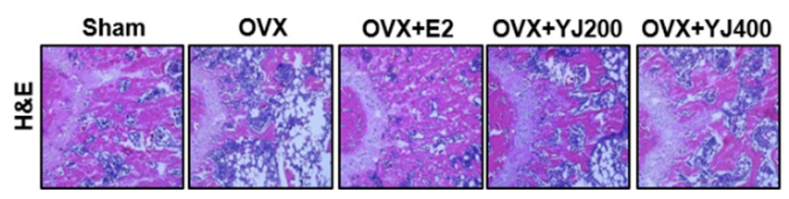

(c)

Figure 8. YJ prevented OVX-mediated bone loss. Nine-week-old SD rats were ovariectomized, and one week later, YJ (200 and $400 \mathrm{mg} / \mathrm{kg}$ ) or PBS was administered orally once a day for 12 weeks. All rats were sacrificed with diethyl ether inhalation at 12 weeks. (a) Representative 3D reconstruction images of femurs from micro-CT. (b) The BV/TV, Tb.Sp, $\mathrm{Tb} . \mathrm{Th}$, and Tb.N were quantified at the left femur. (c) Dissected femora were fixed, decalcified, embedded in paraffin, and sectioned. Sections were stained with hematoxylin and eosin (H\&E). ${ }^{* *} p<0.01$ versus SH group; ${ }^{\#} p<0.05,{ }^{\# \#} p<0.01$ versus the OVX group $(n=6)$.

\section{Discussion}

In the present study, we described that $Y J$ inhibited RANKL-activated osteoclast differentiation and suppressed F-actin ring formation. YJ also showed an inhibitory effect on osteoclastogenesis in a co-culture of osteoblastic cells and bone marrow cells. Furthermore, YJ downregulated RANKL-induced activation of MAP kinases (p38, ERK, and JNK), Akt, I $\mathrm{kB}$, and NF- $\mathrm{kB}$, and the subsequent expression of NFATc1 and c-Fos. In addition, YJ reduced RANKL-mediated NFATc1 nuclear translocation. Consecutively, it inhibited RANKL-induced activation of osteoclast-related genes including TRAP, Atp6V0d2, OSCAR, OC-STAMP, DC-STAMP, calcitonin receptor, MMP-9, and cathepsin K. This study attempted to assess the inhibitory effects of $\mathrm{YJ}$ on osteoclast differentiation in vitro. All in vitro experiments were conducted with a BMM-derived osteoclast culture system.

In 2011, Shim et al. [29] reported four marker components of YJ extracts that were identified using high-performance liquid chromatography (HPLC) analysis. The marker components included paeoniflorin and paeonol in Moutan Cortex Radicis, loganin in Corni Fructus, and 5-hydroxymethyl-2-furaldehyde in Rehmanniae Radix Preparata. In addition, these results further confirmed that $\mathrm{YJ}$ inhibits osteoclast differentiation though inhibiting RANKL-activated MAPKs, NF- $\mathrm{KB}$ activation, and transcription factors in RAW264.7 
cells [29]. Recently, various studies reported that paeoniflorin simultaneously suppresses osteoclastogenesis and facilitates osteoblastogenesis by manipulating the actions of NF$\kappa \mathrm{B}$, whereas paeonol inhibits RANKL-mediated osteoclastogenesis by suppressing p38, ERK, and NF-KB pathways [32,33]. Moreover, 5-HMF inhibits adipogenesis and enhances osteoblastic differentiation of mesenchymal stem cells (MSCs) derived from rat bone [34]. In this study, we identified 5-HMF, Alisol A, diosgenin, loganin, and paeonol from YJ water extract using HPLC analysis. Based on these results, it was demonstrated that the synergistic and complementary effects of these marker components of YJ may contribute to the inhibitory effect of YJ on RANKL-mediated osteoclast differentiation.

Considering the inhibitory effects of YJ on RANKL-mediated osteoclast differentiation and function in vitro, we evaluated the restorative effects of $\mathrm{YJ}$ in OVX-mediated bone loss model in vivo. In this study, YJ improved the reduced BV/TV, Tb.Th, and Tb.N levels in OVX-induced rats in a dose-dependent manner (200 and $400 \mathrm{mg} / \mathrm{kg} /$ day), whereas the increment of $\mathrm{Tb} . \mathrm{Sp}$ was totally reversed. Ha et al. reported that a 13 week repeated oral administration of aqueous $\mathrm{YJ}$ extract in $\mathrm{SD}$ rats indicated no toxicity and the no-observed-adverse-effect-level (NOAEL) was found to be $2000 \mathrm{mg} / \mathrm{kg} /$ day [35]. Additionally, $300 \mathrm{mg} / \mathrm{kg}$ YJ promoted longitudinal bone growth by stimulating chondrocyte proliferation [36]. Based on these results, we used a maximum $400 \mathrm{mg} / \mathrm{kg}$ YJ, once a day, for oral administration in this study.

In conclusion, this study demonstrates that $\mathrm{YJ}$ diminished RANKL-activated osteoclast differentiation via signaling pathways, including MAPKs, Akt, I $\mathrm{B}, \mathrm{NF}-\mathrm{kB}$, and NFATc1, and osteoclast differentiation-related gene expression in vitro. Moreover, $\mathrm{YJ}$ restores bone density in OVX-induced bone destruction in vivo. These findings may help understand the molecular mechanisms of $\mathrm{YJ}$ and provide therapeutic opportunity for the treatment of osteoclast-associated bone diseases.

\section{Materials and Methods}

\subsection{Animals and Reagents}

The animal experiments were conducted in accordance with the guidelines for animal experimentation by the Institutional Committee of Wonkwang University (Approval number: WKU16-52). All animals were obtained from Samtako Bio Inc. (Osan, Korea). The animals were housed under conditions of controlled temperature of $22 \pm 1{ }^{\circ} \mathrm{C}$ with a $12 \mathrm{~h}$ light and $12 \mathrm{~h}$ dark cycle. Human RANKL and M-CSF were purchased from PeproTech EC Ltd. (London, UK). $\mathrm{PGE}_{2}$ and vit $\mathrm{D}_{3}$ were purchased from Sigma-Aldrich (St. Louis, MO, USA). ERK, phospho-ERK, JNK, phospho-JNK, p38, phospho-p38, Akt, phospho-Akt, IKB, phospho-I $\kappa \mathrm{B}, \mathrm{NF}-\kappa \mathrm{B}$, and phospho-NF- $\kappa \mathrm{B}$ were obtained from Cell Signaling Technology Inc. (Beverly, MA, USA). NFATc1, c-Fos, lamin B, and $\beta$-actin were acquired from Santa Cruz Biotechnology, Inc. (Santa Cruz, CA, USA).

\subsection{Preparation of $Y J$}

The YJ formula was purchased from Omniherb Corporation (Daegu, Korea). The composition of YJ was as follows: Rehmanniae Radix Preparata (16 g), Corni Fructus (8 g), Dioscoreae Rhizoma (8 g), Poria (6 g), Alismatis Rhizoma (6 g), and Moutan Cortex Radicis $(6 \mathrm{~g})$. All herbs were immersed in distilled water for $1 \mathrm{~h}$ and then extracted by boiling at $100{ }^{\circ} \mathrm{C}$ for $2 \mathrm{~h}$. The boiled extracts were percolated through filter paper, and the filtrate was concentrated using a rotary evaporator. The concentrate was lyophilized by a freeze dryer (Bondiro, Ilshin, Korea) and stored at $-20^{\circ} \mathrm{C}$. The lyophilized powder was re-suspended in distilled water and used as YJ (Yield: $25.15 \%$ ).

\subsection{HPLC Analysis}

The Agilent 1200 series HPLC system (Agilent Technologies, Santa Clara, CA, USA) consisted of a quaternary pump VL (G7111A), autosampler (G7129A), ICC column oven heater (G7129A), and variable wavelength detector (G7114A). Analyses were carried out on an ZORBOX Eclipse Plus C18 column $(4.6 \times 250 \mathrm{~mm}, 5 \mu \mathrm{m})$ at a flow rate of $0.4 \mathrm{~mL} / \mathrm{min}$. 
The detection wavelength was set at $260 \mathrm{~nm}$. The injection volume was $5 \mu \mathrm{L}$, and the column temperature was maintained at $30{ }^{\circ} \mathrm{C}$. The mobile phase consisted of the solvent $\mathrm{A}$ $(10 \%$ acetonitrile in water containing $0.1 \%$ formic acid) and solvent $\mathrm{B}$ (water) (Table 1 ).

Table 1. Mobile phase condition of chromatographic separation.

\begin{tabular}{cccc}
\hline Time (min) & A & B & $\begin{array}{c}\text { Flow Rate } \\
\text { (mL/min) }\end{array}$ \\
\hline 0 & 15 & 85 & 0.4 \\
30 & 40 & 60 & 0.4 \\
40 & 60 & 40 & 0.4 \\
60 & 100 & 0 & 0.4 \\
\hline
\end{tabular}

\subsection{Cell Culture and Osteoclast Differentiation}

BMCs were separated by marrow flushing of femurs and tibiae excised from male ICR mice (5 weeks old) and cultured in $\alpha$-MEM supplemented with $10 \%$ FBS and $1 \%$ antibiotics. BMCs were seeded onto $100 \mathrm{~mm}$ dishes in medium supplemented with M-CSF (10 ng/mL) for 1 day. After 1 day, non-adherent cells were collected and cultured in the presence of M-CSF (30 ng/mL). After 3 days of incubation, adherent BMMs on dish bottoms were considered as osteoclast precursors and used for subsequent experiments. For osteoclast differentiation, BMMs were cultured in $\alpha$-MEM medium with M-CSF $(30 \mathrm{ng} / \mathrm{mL})$ and RANKL (100 ng/mL) for 4 days. Following this, cells were fixed in $3.7 \%$ formalin, permeabilized with $0.1 \%$ Triton X-100, and stained in TRAP solution. TRAP-positive multinucleated cells (MNCs) with more than three nuclei were counted as osteoclasts.

\subsection{Co-Culture of Osteoblastic and BMCs}

Primary osteoblastic cells were obtained from calvariae of neonatal ICR mice (1 day old). Briefly, after isolation, calvariae were digested with $0.2 \%$ dispase (Roche, Mannheim, Germany) and $0.1 \%$ collagenase (Sigma-Aldrich, St. Louis, MO, USA) for 5 min. Remaining tissues were sequentially digested 4 times for 10 min with the medium obtained after each digestion. Supernatants were accumulated and used as primary osteoblasts. For the co-culture experiments, osteoblasts $\left(1.5 \times 10^{4}\right.$ cells $/ 100 \mathrm{~mm}$ dish $)$ and BMCs $\left(3.5 \times 10^{4} / 100 \mathrm{~mm}\right.$ dish $)$ were co-cultured in medium with $10 \mathrm{nM}$ vit $\mathrm{D}_{3}$ and $100 \mathrm{nM} \mathrm{PGE} 2$ for 7 days.

\subsection{F-Actin Ring Staining}

BMMs were incubated for 4 days with M-CSF and RANKL in the presence or absence of YJ. When the osteoclasts were formed, the cells were washed and fixed with $4 \%$ paraformaldehyde for $20 \mathrm{~min}$ and permeabilized using $0.1 \%$ Triton $\mathrm{X}-100$ for $15 \mathrm{~min}$. Cells were blocked with $2 \%$ BSA for $1 \mathrm{~h}$ and then stained with phalloidin (Molecular Probes, Eugene, OR, USA) for $1 \mathrm{~h}$. Nuclei were stained with DAPI $(0.1 \mu \mathrm{g} / \mathrm{mL})$ for $1 \mathrm{~min}$. The images were acquired using a fluorescence microscope (EVOS FL, AMG, Westburg, Leusden, The Netherlands).

\subsection{Cytotoxicity Assay}

Cytotoxicity was monitored by Cell Proliferation kit II (XTT) (Roche, Mannheim, Germany) according to the supplier's recommendations. BMMs $\left(1 \times 10^{4}\right.$ cells / well, 96well plate) were cultured in $\alpha$-MEM medium supplemented with M-CSF (30 ng $/ \mathrm{mL})$ for $24 \mathrm{~h}$. Cells were treated with YJ $(25,50,100$, or $200 \mu \mathrm{g} / \mathrm{mL})$. After 3 days, XTT solution $(50 \mu \mathrm{L})$ was added to each well and then incubated for $4 \mathrm{~h}$ at $37^{\circ} \mathrm{C}$. Absorbance was measured at $450 \mathrm{~nm}$ using a microplate reader (Molecular Devices, Sunnyvale, CA, USA).

\subsection{Quantitative Real-Time RT-PCR Analysis and RT-PCR}

Total RNA was isolated using the Isol-RNA lysis reagent (PRIME, Gaithersburg, USA) according to the manufacturer's instruction. The RNA samples ( $1 \mathrm{pg}$ ) were reversetranscribed into cDNA using the ReverTra Ace qPCR RT Kit (Toyobo, Osaka, Japan) 
according to the supplier's recommendations. The quantitative real-time RT-PCR was performed using a SYBR ${ }^{\circledR}$ Green Realtime PCR Master Mix (Toyobo, Osaka, Japan) and Step-One Plus ${ }^{\mathrm{TM}}$ RT-PCR system (Applied Biosystems, Foster City, CA, USA). Target gene expression levels were normalized to the expression of the endogenous GAPDH gene and calculated from the cycle threshold $(\mathrm{Ct})$ value using the $2^{-\Delta \Delta} \mathrm{Ct}$ method. Primers used for quantitative real-time RT-PCR are summarized in Table 2. For RT-PCR analysis, the PCR products were electrophoresed on a $1.5 \%$ agarose gel and visualized by ethidium bromide staining.

Table 2. Sequences of real-time RT-PCR primers.

\begin{tabular}{ccc}
\hline Target Gene & & Primer Sequence $\mathbf{( 5}^{\prime}-\mathbf{3}^{\prime} \mathbf{)}$ \\
\hline$c$-Fos & Forward & CTGGTGCAGCCCACTCTGGTC \\
& Reverse & CTTCAGCAGATTGGCAATCTC \\
NFATc1 & Forward & CAACGCCCTGACCACCGATAG \\
& Reverse & GGCTGCCTTCCGTCTCATAGT \\
TRAP & Forward & ACTTCCCCAGCCCTTACTAC \\
& Reverse & TCAGCACATAGCCCACACCG \\
OSCAR & Forward & GAACACCAGAGGCTATGACT \\
& Reverse & CCGTGGAGCTGAGGAAAAGG \\
Atp6v0d2 & Forward & TCAGATCTCTTCAAGGCTGTGCTG \\
& Reverse & GTGCCAAATGAGTTCAGAGTGATG \\
OC-STAMP & Forward & TCACTGACCTGCGTTTCGACAA \\
& Reverse & GCGTAGGCCTGTAGCCACCAA \\
DC-STAMP & Forward & GCAAGGACCCCAAGGAGTCG \\
& Reverse & CAGTTGGCCCAGAAAGAGGG \\
Cathepsin $\mathrm{K}$ & Forward & ACGGAGGCATTGACTCTGAAGATG \\
& Reverse & GTTGTTCTTATTCCGAGCCAAGAG \\
Calcitonin receptor & Forward & TGGTTGAGGTTGTGCCCA \\
& Reverse & CTCGTGGGTTGCCTCATC \\
MMP-9 & Forward & TCCAACCTCACGGACACCC \\
& Reverse & AGCAAAGCCGGCCGTAGA \\
GAPDH & Forward & ACCACAGTCCATGCCATCAC \\
& Reverse & TCCACCACCCTGTTGCTGTA \\
\hline
\end{tabular}

\subsection{Western Blotting}

Whole cells were washed with $1 \times$ PBS and then lysed with ice-cold lysis buffer (Biosesang, Seongnam, Korea) consisting of $\mathrm{Na}_{3} \mathrm{VO}_{4}$ and protease inhibitor cocktail. Cell lysates were centrifuged for $20 \mathrm{~min}$, and the supernatants were collected. Total proteins were resolved by $10 \%$ sodium dodecyl sulfate-polyacrylamide gel electrophoresis and transferred to polyvinylidene difluoride membrane (Bio-Rad, Hercules, CA, USA). The membranes were blocked with 5\% BSA for $1 \mathrm{~h}$ and incubated with primary antibodies overnight. These antibodies were probed using HRP-conjugated secondary antibodies. Chemiluminescent signals were detected with Western ECL solution (Bio-rad, Hercules, CA, USA). Nuclear/cytosol proteins were isolated using a nuclear/cytosol fractionation kit (BioVision, Mountain View, CA, USA).

\subsection{Luciferase Reporter Assay}

293T cells were cultured in DMEM medium containing 10\% FBS and plated for $24 \mathrm{~h}$ before transfection in a 96-well plate at $2 \times 10^{4}$ cells/well. The cells were co-transfected with TRAF6 and NF-kB luciferase reporter vector (pGL3-Basic Vector; Promega, Madison, WI, USA) for $3 \mathrm{~h}$ in serum-free medium. After $12 \mathrm{~h}$, the transfected cells were incubated with or without YJ. The cells were lysed with $1 \times$ lysis buffer at room temperature for $15 \mathrm{~min}$, and luciferase activity was assayed using a luciferase assay system (Promega, Madison, WI, USA). 


\subsection{Immunocytochemistry Analysis}

BMMs were stimulated with M-CSF and RANKL in the presence or absence of YJ. After $48 \mathrm{~h}$, the cells were fixed in $4 \%$ paraformaldehyde (Tech \& Innovation, Gangwon, Korea) and permeabilized with $0.1 \%$ Triton X-100. After blocking with 5\% BSA for $1 \mathrm{~h}$, the cells were incubated with anti-NFATc1 antibody (1:500). Cells were rinsed with $1 \times$ PBS and incubated with the secondary antibody (1:200) for $1 \mathrm{~h}$ and stained with DAPI. Fluorescent images were examined using a fluorescence microscope.

\subsection{OVX-Mediated Bone Loss Model}

Female Sprague-Dawley (SD, 8 weeks old) rats were randomly divided into five groups. After 1 week acclimatization, rats were anesthetized with a ketamine-xylazine mixture (5:1, I.P.), and the ovaries were removed bilaterally. One week after surgery, rats were divided into five main experimental groups (6 rats/group): (1) sham-operated (SH); (2) OVX; (3) OVX rats which received 17ß-estradiol (E2, $100 \mu \mathrm{g} / \mathrm{kg}$ once daily, S.C.); (4) OVX rats treated with low doses of $\mathrm{YJ}(200 \mathrm{mg} / \mathrm{kg}$, P.O.); (5) OVX rats treated with high doses of YJ (400 mg/kg, P.O.). Osteoporosis induced by ovariectomy is associated with estrogen deficiency; $17 \beta$-estradiol was used as the positive drug. The rats were euthanized at 12 weeks by diethyl ether inhalation, and the femurs were isolated for micro-CT (Skyscan 1076, Bruker, Kontich, Belgium) and histological analysis.

\subsection{Micro-CT and Histological Analysis}

The left femur was examined with a Skyscan 1076 scanner at a $35 \mu \mathrm{m}$ resolution. The X-ray source was set at a $50 \mathrm{kV}$ accelerating voltage and $100 \mu \mathrm{A}$ beam current with a $0.5 \mathrm{~mm}$ aluminum (Al) filter. Raw scan images were reconstructed by Skyscan NRecon software (ver.1.6.10.1, Bruker, Kontich, Belgium). Reconstructed images were segmented to allow for trabecular bone structure quantification using CTAn software (ver.1.18.4.0, Bruker, Kontich, Belgium). 3D image visualization was performed with the Ant software (ver.2.4, Bruker, Kontich, Belgium). The right femurs were fixed in $4 \%$ paraformaldehyde for 1 day, decalcified in 12\% ethylenediaminetetraacetic acid (EDTA, pH 7.4) for 3 weeks at room temperature. Then, femurs were embedded in paraffin. Serial sections were sliced into $5 \mu \mathrm{m}$ using a microtome (RM2125, Leica Microsystems, Bannockburn, IL, USA) and were subjected to H\&E staining.

\subsection{Statistical Analysis}

The results were expressed as the mean \pm standard deviation. Statistical analyses were performed by the Student's $t$-test and one-way ANOVA using SPSS Software (Korean version 12.0; SPSS Inc., Chicago, IL, USA). The Student's $t$-test was used for comparisons of two means, and one-way ANOVA followed by post hoc analysis using the LSD test was carried out for multiple comparisons. To check for normal distribution and homogeneity of variance we used Levene's test. The Levene's test statistical significance was greater than 0.05 , assuming equal variances. In the case of unequal-variances, we performed the Kruskal-Wallis test and the Mann-Whitney U test, which are nonparametric statistics. Values of $p<0.05$ were considered to represent a significant difference.

Author Contributions: Conceptualization, S.-Y.H. and Y.-K.K.; methodology, S.-Y.H.; software, S.-Y.H.; validation, S.-Y.H. and Y.-K.K.; formal analysis, S.-Y.H.; investigation, S.-Y.H.; resources, S.-Y.H. and Y.-K.K.; data curation, S.-Y.H.; writing-original draft preparation, S.-Y.H. and Y.-K.K.; writing-review and editing, S.-Y.H. and Y.-K.K.; visualization, S.-Y.H.; supervision, Y.-K.K.; project administration S.-Y.H. and Y.-K.K.; funding acquisition, S.-Y.H. All authors have read and agreed to the published version of the manuscript.

Funding: This research was funded by National Research Foundation (NRF) of Korea (grant number: NRF-2019R1C1C1002761).

Institutional Review Board Statement: The study was approved according to the Wonkwang University Institutional Animal Care and Use Committee (WKU16-52). 
Informed Consent Statement: Not applicable.

Data Availability Statement: The data presented in this study are available within this article.

Conflicts of Interest: The authors declare no conflict of interest.

Sample Availability: Samples of the YJ extracts are available from the authors.

\section{References}

1. Lerner, U. Bone Remodeling in Post-menopausal Osteoporosis. J. Dent. Res. 2006, 85, 584-595. [CrossRef]

2. Sözen, T.; Özışık, L.; Başaran, N.Ç. An overview and management of osteoporosis. Eur. J. Rheumatol. 2017, 4, 46-56. [CrossRef]

3. Cosman, F.; de Beur, S.J.; LeBoff, M.S.; Lewiecki, E.M.; Tanner, B.; Randall, S.; Lindsay, R. Clinician's Guide to Prevention and Treatment of Osteoporosis. Osteoporos. Int. 2014, 25, 2359-2381. [CrossRef] [PubMed]

4. Hannan, M.T.; Felson, D.T.; Dawson-Hughes, B.; Tucker, K.L.; Cupples, L.A.; Wilson, P.W.F.; Kiel, D.P. Risk Factors for Longitudinal Bone Loss in Elderly Men and Women: The Framingham Osteoporosis Study. J. Bone Miner. Res. 2010, 15, 710-720. [CrossRef]

5. Chen, L.-R.; Ko, N.-Y.; Chen, K.-H. Medical Treatment for Osteoporosis: From Molecular to Clinical Opinions. Int. J. Mol. Sci. 2019, 20, 2213. [CrossRef] [PubMed]

6. Canalis, E. Management of endocrine disease: Novel anabolic treatments for osteoporosis. Eur. J. Endocrinol. 2018, 178, R33-R44. [CrossRef]

7. Fierro, F.A.; Nolta, J.A.; Adamopoulos, I.E. Concise Review: Stem Cells in Osteoimmunology. Stem Cell 2017, $35,1461-1467$. [CrossRef]

8. Feng, X.; McDonald, J.M. Disorders of Bone Remodeling. Annu. Rev. Pathol. Mech. Dis. 2011, 6, 121-145. [CrossRef] [PubMed]

9. Tanaka, S.; Takahashi, N.; Udagawa, N.; Tamura, T.; Akatsu, T.; Stanley, E.R.; Kurokawa, T.; Suda, T. Macrophage colonystimulating factor is indispensable for both proliferation and differentiation of osteoclast progenitors. J. Clin. Investig. 1993, 91, 257-263. [CrossRef]

10. Fuller, K.; Wong, B.; Fox, S.; Choi, Y.W.; Chambers, T.J. TRANCE is necessary and sufficient for osteoblast-mediated activation of bone resorption in osteoclasts. J. Exp. Med. 1998, 188, 997-1001. [CrossRef] [PubMed]

11. Ross, F.P. M-CSF, c-Fms, and Signaling in Osteoclasts and their Precursors. Ann. N. Y. Acad. Sci. 2006, 1068, 110-116. [CrossRef] [PubMed]

12. Wong, B.R.; Besser, D.; Kim, N.; Arron, J.; Vologodskaia, M.; Hanafusa, H.; Choi, Y. TRANCE, a TNF Family Member, Activates Akt/PKB through a Signaling Complex Involving TRAF6 and c-Src. Mol. Cell 1999, 4, 1041-1049. [CrossRef]

13. Simonet, W.; Lacey, D.; Dunstan, C.; Kelley, M.; Chang, M.-S.; Lüthy, R.; Nguyen, H.; Wooden, S.; Bennett, L.; Boone, T.; et al. Osteoprotegerin: A Novel Secreted Protein Involved in the Regulation of Bone Density. Cell 1997, 89, 309-319. [CrossRef]

14. Lacey, D.L.; Timms, E.; Tan, H.L.; Kelley, M.J.; Dunstan, C.R.; Burgess, T.; Elliott, R.; Colombero, A.; Elliott, G.; Scully, S.; et al. Osteoprotegerin ligand is a cytokine that regulates osteoclast differentiation and activation. Cell 1998, 93, 165-176. [CrossRef]

15. Takayanagi, H.; Kim, S.; Koga, T.; Nishina, H.; Isshiki, M.; Yoshida, H.; Saiura, A.; Isobe, M.; Yokochi, T.; Inoue, J.-I.; et al. Induction and Activation of the Transcription Factor NFATc1 (NFAT2) Integrate RANKL Signaling in Terminal Differentiation of Osteoclasts. Dev. Cell 2002, 3, 889-901. [CrossRef]

16. Ovitt, C.; Grigoriadis, A.E. Bone and haematopoietic defects in mice lacking c-fos. Nature 1992, 360, 741-745. [CrossRef]

17. Kobayashi, N.; Kadono, Y.; Naito, A.; Matsumoto, K.; Yamamoto, T.; Tanaka, S.; Inoue, J.-I. Segregation of TRAF6-mediated signaling pathways clarifies its role in osteoclastogenesis. EMBO J. 2001, 20, 1271-1280. [CrossRef] [PubMed]

18. Gravallese, E.M.; Harada, Y.; Wang, J.T.; Gorn, A.H.; Thornhill, T.S.; Goldring, S.R. Identification of cell types respon-sible for bone resorption in rheumatoid arthritis and juvenile rheumatoid arthritis. Am. J. Pathol. 1998, 152, 943.

19. Barrow, A.D.; Raynal, N.; Andersen, T.L.; Slatter, D.A.; Bihan, D.; Pugh, N.; Cella, M.; Kim, T.; Rho, J.; Negishi-Koga, T.; et al. OSCAR is a collagen receptor that costimulates osteoclastogenesis in DAP12-deficient humans and mice. J. Clin. Investig. 2011, 121, 3505-3516. [CrossRef]

20. Okada, Y.; Naka, K.; Kawamura, K.; Matsumoto, T.; Nakanishi, I.; Fujimoto, N.; Sato, H.; Seiki, M. Localization of matrix metalloproteinase 9 (92-kilodalton gelatinase/type IV collagenase = gelatinase B) in osteoclasts: Implications for bone resorption. Lab. Investig. 1995, 72, 311-322.

21. Nakashima, T.; Takayanagi, H. Osteoimmunology: Crosstalk between the Immune and Bone Systems. J. Clin. Immunol. 2009, 29, 555-567. [CrossRef] [PubMed]

22. Kim, K.; Lee, S.-H.; Ha Kim, J.; Choi, Y.; Kim, N. NFATc1 Induces Osteoclast Fusion via Up-Regulation of Atp6v0d2 and the Dendritic Cell-Specific Transmembrane Protein (DC-STAMP). Mol. Endocrinol. 2008, 22, 176-185. [CrossRef] [PubMed]

23. Yuhong, H.; Qian, L.; Yu, L.; Yingqiang, Z.; Yanfen, L.; Shujing, Y.; Shufang, Q.; Lanjun, S.; Shuxuan, Z.; Baohe, W. An n-of-1 Trial Service in Clinical Practice: Testing the Effectiveness of Liuwei Dihuang Decoction for Kidney-Yin Deficiency Syndrome. Evid.-Based Complement. Altern. Med. 2013, 2013, 827915. [CrossRef]

24. Kang, D.G.; Sohn, E.J.; Moon, M.K.; Mun, Y.J.; Woo, W.H.; Kim, M.K.; Lee, H.S. Yukmijihwang-tang ameliorates ischemia/reperfusion-induced renal injury in rats. J. Ethnopharmacol. 2006, 104, 47-53. [CrossRef] 
25. Huang, Y.; Zhang, H.; Yang, S.; Qiao, H.; Zhou, W.; Zhang, Y. Liuwei Dihuang decoction facilitates the induction of long-term potentiation (LTP) in senescence accelerated mouse/prone 8 (SAMP8) hippocampal slices by inhibiting volt-age-dependent calcium channels (VDCCs) and promoting N-methyl-D-aspartate receptor (NMDA) receptors. J. Ethnopharmacol. 2012, 140, 384-390.

26. Perry, B.; Zhang, J.; Sun, C.; Saleh, T.; Wang, Y. Liuwei Dihuang Lowers Body Weight and Improves Insulin and Leptin Sensitivity in Obese Rats. Evid.-Based Complement. Altern. Med. 2011, 2012, 847167. [CrossRef]

27. Song, X.-Y.; Chen, Q.; Qi, X.-Y. Effect of liuwei dihuang pill on erythrocyte aldose reductase activity in early diabetic nephropathy patients. Zhongguo Zhong Xi Yi Jie He Za Zhi Zhongguo Zhongxiyi Jiehe Zazhi = Chin. J. Integr. Tradit. West. Med. 2004, 24, 1087-1090.

28. Szeto, Y.-T.; Lei, P.-C.; Ngai, K.-L.; Yiu, A.T.-W.; Chan, C.S.-P.; Kok, E.W.-F.; Leong, C.-W. An in vitro study of the antioxidant activities and effect on human DNA of the Chinese herbal decoction 'Liu Wei Di Huang'. Int. J. Food Sci. Nutr. 2009, 60, 1-6. [CrossRef]

29. Shim, K.S.; Ma, C.J.; Kim, D.S.; Ma, J.Y. Yukmijihwang-tang inhibits receptor activator for nuclear Factor-kappaB lig-and-induced osteoclast differentiation. J. Med. Food 2011, 14, 1439-1447. [CrossRef] [PubMed]

30. Jin, U.-H.; Kim, N.-I.; Lee, T.-K.; Lee, D.-N.; Kim, J.-K.; Lee, I.-S.; Kim, C.-H. Herbal formulation, Yukmi-jihang-tang-Jahage, regulates bone resorption by inhibition of phosphorylation mediated by tyrosine kinase Src and cyclooxygenase expression. $J$. Ethnopharmacol. 2006, 106, 333-343. [CrossRef]

31. Yamashita, T.; Yao, Z.; Li, F.; Zhang, Q.; Badell, I.R.; Schwarz, E.M.; Takeshita, S.; Wagner, E.F.; Noda, M.; Matsuo, K.; et al. NF-kappaB p50 and p52 regulate receptor activator of NF-kappaB ligand (RANKL) and tumor ne-crosis factor-induced osteoclast precursor differentiation by activating c-Fos and NFATc1. J. Biol. Chem. 2007, 282, 18245-18253. [CrossRef]

32. Wang, Y.; Dai, J.; Zhu, Y.; Zhong, W.; Lu, S.; Chen, H.; Chai, Y. Paeoniflorin regulates osteoclastogenesis and osteoblastogenesis via manipulating NF-kB signaling pathway both in vitro and in vivo. Oncotarget 2017, 9, 7372-7388. [CrossRef]

33. Tsai, H.Y.; Lin, H.Y.; Fong, Y.C.; Wu, J.B.; Chen, Y.F.; Tsuzuki, M.; Tang, C.H. Paeonol inhibits RANKL-induced osteoclastogenesis by inhibiting ERK, p38 and NF-kappaB pathway. Eur. J. Pharmacol. 2008, 588, 124-133. [CrossRef] [PubMed]

34. Tan, X.-L.; Zhang, Y.-H.; Cai, J.-P.; Zhu, L.-H.; Ge, W.-J.; Zhang, X. 5-(Hydroxymethyl)-2-furaldehyde Inhibits Adipogenic and Enhances Osteogenic Differentiation of Rat Bone Mesenchymal Stem Cells. Nat. Prod. Commun. 2014, 9, 529-532. [CrossRef] [PubMed]

35. Ha, H.; Lee, J.K.; Lee, H.Y.; Koh, W.S.; Seo, C.S.; Lee, M.Y.; Huang, D.S.; Shin, H. Safety Evaluation of Yukmiji-hwang-tang: Assessment of Acute and Subchronic Toxicity in Rats. Evid. Based Complement. Alternat. Med. 2011, 2011, 672136. [CrossRef] [PubMed]

36. Cho, S.-M.; Lee, S.H.; Lee, D.; Lee, J.H.; Chang, G.T.; Kim, H.; Lee, J.Y. The Korean herbal formulation Yukmiji-hwangtang stimulates longitudinal bone growth in animal models. BMC Complement. Altern. Med. 2017, 17, 239. [CrossRef] 